\title{
Modern extraction techniques optimized to extract betacyanins from Gomphrena globosa L.
}

\author{
Custódio Lobo Roriz ${ }^{\mathrm{a}, \mathrm{b}}$, Lillian Barros ${ }^{\mathrm{a}, \mathrm{c}, *}$, M.A. Prieto ${ }^{\mathrm{a}, \mathrm{d}}$, Maria Filomena Barreiro ${ }^{\mathrm{c}}$, \\ Patricia Morales $^{\mathrm{b}}$, Isabel C.F.R. Ferreira ${ }^{\mathrm{a}, *}$

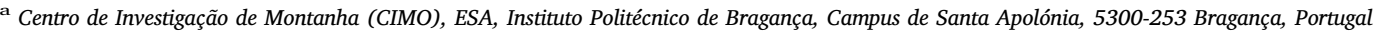 \\ ${ }^{\mathrm{b}}$ Dpto. Nutrición y Bromatología II, Facultad de Farmacia. Universidad Complutense de Madrid (UCM), Plaza Ramón y Cajal, s/n, E-28040 Madrid, Spain \\ ${ }^{\mathrm{c}}$ Laboratory of Separation and Reaction Engineering - Laboratory of Catalysis and Materials (LSRE-LCM), Polytechnic Institute of Bragança, Campus de Santa Apolónia, \\ 1134, 5301-857 Bragança, Portugal \\ d Nutrition and Bromatology Group, Faculty of Food Science and Technology, University of Vigo, Ourense Campus, E32004 Ourense, Spain
}

\section{A R T I C L E I N F O}

\section{Keywords:}

Gomphrena globosa L.

Betacyanin

Natural colorant

Microwave extraction

Ultrasound extraction

Response surface methodology

\begin{abstract}
A B S T R A C T
Gomphrena globosa L. is a source of betacyanins, molecules with high colorant power. In order to replace conventional extraction techniques, microwave (MAE) and ultrasound assisted extraction (UAE) processes were optimized by the response surface methodology (RSM) to maximize the recovery of betacyanins from G. globosa. A five-level full factorial design of 24 combinations and 4 replicates was implemented for MAE and UAE. The optimum processing conditions for $\mathrm{MAE}\left(t=8 \mathrm{~min} ; T=60^{\circ} \mathrm{C} ; E t=0 \%\right.$; and $\left.S / L=5 \mathrm{~g} / \mathrm{L}\right)$ conducted to an extraction yield of $39.6 \pm 1.8 \mathrm{mg} / \mathrm{g}$ dry weight, while for UAE ( $t=22 \mathrm{~min} ; P=500 \%$; $E t=0 \%$; and $S$ / $L=5 \mathrm{~g} / \mathrm{L}$ ) a value of $46.9 \pm 4.8 \mathrm{mg} / \mathrm{g}$ was achieved, validating the UAE more suitable to obtain the target compounds. This technique can provide extracts rich in betacyanins and with high potential to be used as natural colorants.
\end{abstract}

\section{Introduction}

Alkaloids are a group of metabolites that can be found in a wide variety of natural sources. These compounds are characterized by the presence of, at least, one nitrogen, commonly in a cyclic structure, representing the main factor of the displayed pharmacological activity. Despite of this common element, alkaloids can present a huge range of different chemical structures, for instance in plants, they can be divided into more than 25 different subgroups. Within their chemical diversity, which includes a wide range of structures, several biological and pharmacological properties can be observed (Klein-júnior et al., 2016). Betalains, pigments belonging to a class of secondary metabolites synthesized from tyrosine, are a group of chromoalkaloids, which are divided in betacyanins (red-violet pigments) and betaxanthins (yellow pigments) (Junqueira-Goncalves et al., 2011). Although structurally related to alkaloids, betacyanins do not present toxic effects.

These pigments have received great attention because of their proven antiviral and antimicrobial activities, among others (DelgadoVargas et al., 2000). Moreover, these compounds, especially regarding their use as colorants in the food industry, offer the possibility to replace the chemical synthetic counterparts, such as azo-dyes. Addi- tionally, these compounds can confer, over the colouring power, also functional properties (Gengatharan et al., 2015).

Even though betacyanins are associated mostly with Beta vulgaris L., several plants such as Hylocereus polyrhizus (Weber) Britton \& Rose, Opuntia ficus-indica [L.] Miller, Opuntia stricta (Haw.) Haw., Rivina humilis L. and G. globosa, (Martins et al., 2016), present these compounds in their composition. Despite not being widely studied, $G$. globosa is particularly rich in betacyanins, making this plant an excellent source for obtaining this type of compounds.

For pigment extractions, several techniques can be applied, from traditional ones such as maceration, a good example since the achieved extraction yields are very acceptable (Roriz et al., 2017) to more contemporary approaches. In this context, in the last few years, several methods have emerged for the extraction of plant bioactive compounds, such as enzyme assisted extraction, accelerated extraction methods, microwave assisted extraction (MAE), and ultrasound assisted extraction (UAE) (Chavan and Singhal, 2013). When compared with traditional techniques, they feature a variety of advantages, such lower solvent consumption and increased extraction efficiency (Heleno et al., 2016). For instance, MAE, a green extraction methodology, is gaining relevance due to its high extraction efficiency, and achievement of

\footnotetext{
* Corresponding authors at: Centro de Investigação de Montanha (CIMO), ESA, Instituto Politécnico de Bragança, Campus de Santa Apolónia, $5300-253$ Bragança, Portugal.

E-mail addresses: lillian@ipb.pt (L. Barros), iferreira@ipb.pt (I.C.F.R. Ferreira).
} 


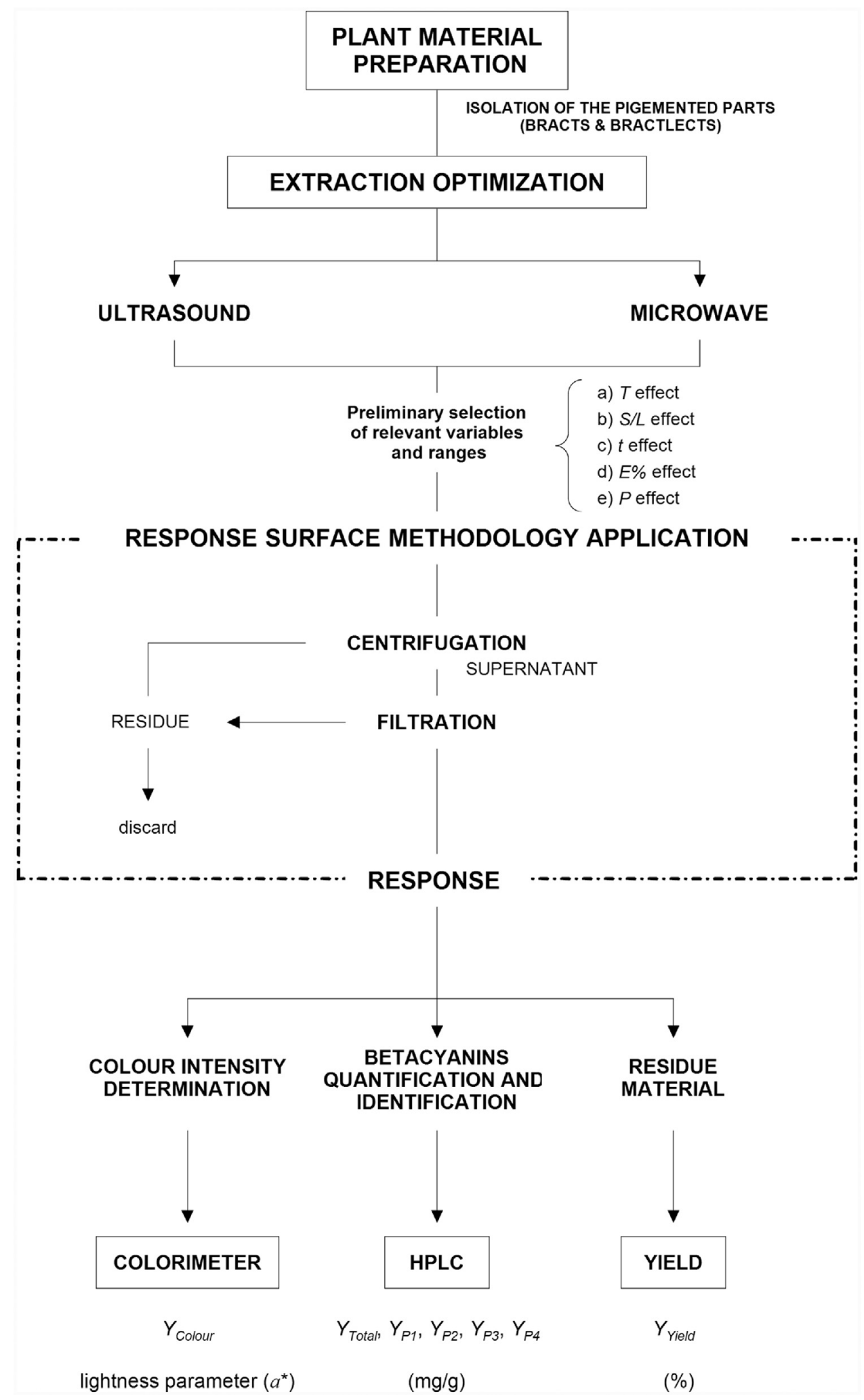

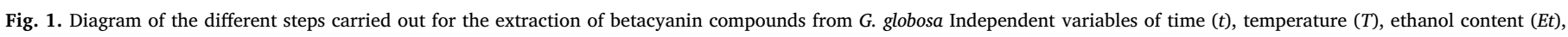

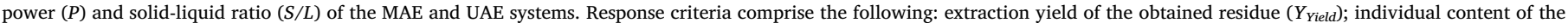

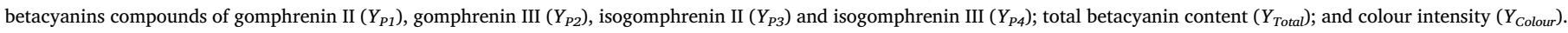

products with superior quality at a much lower cost (Pinela et al., 2016b). Among all the mentioned advantages, UAE offers particular advantages, such as mechanical effects, which allow a greater solvent penetration within the matrix, thus increasing the contact area solid/ liquid (Hossain et al., 2014).
Several parameters can be controlled to increase MAE and UAE extraction efficiency, including several process variables that require individual consideration, independently of the applied extraction technic to recover the target compounds from natural matrices. Therefore, it is essential to identify the main variables prior to the 
optimization process, and maximize their responses considering the minimum time, energy and solvent consumption to design the most cost-effective and profitable extraction system (Dai and Mumper, 2010). The most frequent form to carry out an optimization is to measure, independently, the influence of each variable whereas all the others are fixed. Nevertheless, the application of mathematical models such as the one of response surface methodology (RSM) is gaining visibility within the scientific community. The RSM design allows to optimize, simultaneously, all the variables and to predict the most efficient conditions. This is achieved by using second order polynomial models with interactions, which are able to describe and maximize the selected response criteria, based on the tested experimental range (Bezerra et al., 2008; Kalil and Maugeri, 2000; Pinela et al., 2016b).

Therefore, the aim of this work was to study the association of MAE and UAE, and use RSM to obtain and identify the optimal points for the extraction of betacyanins from $G$. globosa, a promising source of novel alternative natural colorant additives for the food industrial sector.

\section{Material and methods}

\subsection{Samples}

The plant material, G. globosa, was acquired from a Portuguese company, Ervital, which is based in Castro Daire, a highland area full of diversity. This company has its own harvesting based on organic farming principles. They commercialize several certified plant materials from great plant diversity. Ana Maria Carvalho, person in charge of the medicinal plant collection of the Herbarium of the Agriculture School of the Polytechnic Institute of Bragança (Trás-os-Montes, Portugal), was the responsible for the botanical identification of the plant material. The plants were subjected to mechanical separation to isolate the flowers, bracts and bracteoles, the pigmented parts of the plant, from the inflorescence, in order to increase the extraction efficiency. The flowers, bract and bracteoles, separated from the bract-like leaf-pair and heads, were put into a rotary sieve device to be blended and sieved $(2 \mu \mathrm{m})$. The obtained powder (pigmented parts) was further mixed to guarantee sample homogeneity and stored, protected from light, in a desiccator at room temperature (average $25^{\circ} \mathrm{C}$ ), until analysis.

\subsection{Standards and reagents}

Acetonitrile of HPLC grade and ethanol p.a. were purchase from Fisher Scientific (Lisbon, Portugal). The standard (betalain) was acquired from Sigma (St. Louis, MO, USA). Water was treated in a Milli-Q water purification system (TGI Pure Water Systems, Greenville, SC, USA). All other chemicals and solvents were of analytical grade and purchased from common suppliers.

\subsection{Betacyanin extraction}

\subsubsection{Microwave-assisted extraction}

The MAE process was performed in a Biotage Initiator Microwave (Biotage $^{\varpi}$ Initiator $^{+}$, Uppsala, Sweden) in closed vessels of highprecision glass. The solvent volume, an ethanol-water mixture, was fixed at $20 \mathrm{~mL}$. The samples were extracted according to different conditions regarding time $(t)$, temperature $(T)$, ethanol content $(E t)$ and solid/liquid ratio $(S / L)$, defined as the independent variables by the RSM design (supplementary material, Fig. 1 and Table A1). During processing, samples were stirred at $600 \mathrm{rpm}$ using a magnetic stirring bar. After applying the established microwave power and time, the mixture in the extraction vessel was quickly cooled in the processing chamber.

\subsubsection{Ultrasound assisted extraction}

The UAE was carried out using an ultrasonic device (QSonica sonicators, model CL-334, Newtown, CT, USA), equipped with a digital timer, and working in the range of $100-500 \mathrm{~W}$, at a frequency of $20 \mathrm{kHz}$. The used solvent volume was settled at $50 \mathrm{~mL}$. The samples were extracted according to different conditions regarding $t$, power $(P)$, $E t$ and $S / L$, as defined by the RSM design (Fig. 1 and Table A1).

After the microwave and ultrasonic extractions, the mixtures were centrifuged at $14000 \mathrm{rpm}$ for $10 \mathrm{~min}$. The solid was discarded and the supernatant divided into two parts. One part was used to quantify the extraction yield and measure the light intensity using a colorimeter (Minolta spectrophotometer, Konica Minolta Sensing, Inc., Chroma Meter CR-400, Japan). The second part was carefully collected into a glass vial, filtered through $0.2 \mu \mathrm{m}$ nylon filters (Whatman), and used directly to quantify the total betacyanin content by HPLC-DAD analysis.

\subsubsection{Extraction yield determination}

The extraction yield was determined gravimetrically. For that, a sample (10 mL) of the filtered solution was dried in an oven, firstly at $60{ }^{\circ} \mathrm{C}$ to evaporate the ethanol, then at $100{ }^{\circ} \mathrm{C}$ to evaporate the residual water. After complete sample dryness, the achieved solid residue was removed from the oven and allowed to cool before weighting. Extraction yield was thereafter expressed as the ratio between the mass of the achieved residue (determined by difference) and the mass of the corresponding original plant material.

\subsubsection{Colour parameters analysis}

A Minolta spectrophotometer (Konica Minolta Sensing, Inc., Chroma Meter CR-400, Japan) was used to measure the colour of the extract powder. Using the illuminaçnt $\mathrm{C}$ and a diaphragm aperture of $8 \mathrm{~mm}$, the CIE $L * a * b *$ colour space values were reported through the computerized system using the colour data software Spectra Magic Nx (version CM-S100W 2.03.0006, Konica Minolta Company, Japan). Average values were considered to determine the colour coordinates, where $L^{*}$ represents lightness, $a^{*}$ represents chromaticity on a green $(-)$ to red $(+)$ axis, and $b^{*}$ represents chromaticity on a blue $(-)$ to yellow (+) axis. Since the colour of interest was the red, only parameter $a^{*}$ measurements were taken into account for further analysis. The instrument was calibrated with standard white tiles before analysis (Spectra Magic NX Instruction Manual, Konica Minolta Sensing, Inc. (ver. 2.0), 2009, Japan).

\subsubsection{Betacyanins analysis and quantification}

For betacyanin determination HPLC-DAD analyses were performed with a Dionex Ultimate 3000 UPLC instrument (Thermo Scientific, San Jose, CA, USA) coupled with a diode-array detector. A quaternary pump, an autosampler maintained at $5{ }^{\circ} \mathrm{C}$, a degasser a photodiodearray detector and an automatic thermostatic column compartment constitute the chromatographic system. The separation was carried out in a Waters Spherisorb S3 ODS-2 C18, $(3 \mu \mathrm{m}, 4.6 \mathrm{~mm} \times 150 \mathrm{~mm}$, Waters, Milford, MA, USA) column operating at $35^{\circ} \mathrm{C}$. The solvents used were: (A) $0.1 \%$ trifluoracetic acid (TFA) in water and (B) acetonitrile. The gradient elution programing, performed using a flow rate of $0.5 \mathrm{~mL} / \mathrm{min}$, was as follows: $10 \% \mathrm{~B}$ for $3 \mathrm{~min}$, from 10 to $15 \% \mathrm{~B}$ for $12 \mathrm{~min}, 15 \%$ B for $5 \mathrm{~min}$, from 15 to $18 \%$ B for $5 \mathrm{~min}$, from 18 to $30 \%$ B for $20 \mathrm{~min}$, from 30 to $35 \%$ B for $5 \mathrm{~min}$, and from 35 to $10 \% \mathrm{~B}$ for $10 \mathrm{~min}$, resulting in a total run time of $60 \mathrm{~min}$, plus $10 \mathrm{~min}$ for column reconditioning. Betacyanins maximum absorbance is $530 \mathrm{~nm}$, therefore this was preference wavelength used to recorded all chromatograms.

The identification of these compounds was previously performed by authors (Roriz et al., 2014) and confirmed in this study. Four betacyanin compounds were found: gomphrenin II (P1), gomphrenin III (P2), isogomphrenin II (P3) and isogomphrenin III (P4). For quantitative analysis, a calibration curve was obtained based on gomphrenin III, and results were expressed as mg per $g$ of plant dry weight $(\mathrm{dw})$. 


\subsection{Experimental design, model analysis and statistical evaluation}

\subsubsection{Experimental design}

The influence of different independent variables was investigated using one-factor-at-a-time to select the significant ones and determine the preliminary range of the processing variables. Based on these experimental results (data not shown), the selected significant variables for the RMS design were: $X_{1}$ (time in min), $X_{2}$ (temperature in ${ }^{\circ} \mathrm{C}$ or power in W, if it applies MAE or UAE, respectively), $X_{3}$ (ethanol content in\%) and $X_{4}$ (solid/liquid ratio in $\mathrm{g} / \mathrm{L}$ ). Therefore, the combined effect of these four variables on betacyanins extraction was studied using circumscribed central composite design (CCCD) as proposed by Box and Hunter (1957). The responses were solved using 24 independent combinations and four replicates as the centre of the experimental design. In this design, the points of experiments are generated on a sphere around the centre point. The centre point is supposed to be an optimum position for the response and is repeated to maximize the prediction (Box et al., 2005). This design also requires five levels for each factor. Experimental runs were randomized to minimize the effects of unexpected variability in the observed responses. A detailed description of the mathematical expressions to calculate the design distribution and to decode and code the tested variable's ranges is presented in the supplementary material section (Fig. 1 and Table A1).

\subsubsection{Mathematical model}

The response surface models were fitted by means of least-squares calculation using the following second-order polynomial equation:

$Y=b_{0}+\sum_{i=1}^{n} b_{i} X_{i}+\sum_{\substack{i=1 \\ j>i}}^{n-1} \sum_{j=2}^{n} b_{i j} X_{i} X_{j}+\sum_{i=1}^{n} b_{i i} X_{i}^{2}$

where $Y$ is the dependent variable (response variable) to be modelled, $X_{i}$ and $X_{j}$ define the independent variables, $b_{o}$ is the constant coefficient, $b_{i}$ is the coefficient of linear effect, $b_{i j}$ is the coefficient of interaction effect, $b_{i i}$ the coefficient of quadratic effect and $n$ is the number of variables. The dependent variable responses, for each extraction technique (MAE and UAE), were the following: extract yield ( $Y_{\text {Yield }}$ ), determined gravimetrically, colour $\left(Y_{\text {Colour }}\right)$, determined as the analytical colour parameter $a^{*}$, total content of betacyanins $\left(Y_{\text {Total }}\right)$, and individual content of each betacyanin P1-P4 $\left(Y_{P 1}-Y_{P 4}\right)$. The two last responses were evaluated based on the quantification achieved by HPLC-DAD analysis.

\subsubsection{Procedure to optimize the variables to a maximum response}

For response optimization, a maximization process was applied using a simple method tool to solve non-linear problems (Heleno et al., 2016; Pinela et al., 2016a). Constraints were imposed to the variable coded values to avoid unnatural conditions (i.e., times lower than 0 ).

\subsection{Fitting procedures and statistical analysis}

The fitting procedures applied to the responses were performed on a Microsoft Excel spreadsheet. Coefficient estimations and statistical calculations of the proposed experimental equations were carried out in three phases:

- Coefficients estimation was obtained by minimization the sum of quadratic differences between the observed and model-predicted values, using the nonlinear least-squares (quasi-Newton) method provided by the macro Solver in Microsoft Excel (Kemmer and Keller, 2010).

- The significance of the coefficients of the parametric confidence intervals was calculated using the "SolverAid" (Prikler, 2009). The model was simplified by dropping terms, which were not statistically significant ( $p$-value $>0.05$ ).
- The uniformity of the model was checked by applying the following statistical assessment criteria: a) The Fisher $F$-test $(\alpha=0.05)$ was used to determine whether the constructed models were consistent to describe the observed data; b) The 'SolverStat' macro was used for the assessment of the parameter and model prediction uncertainties (Comuzzi et al., 2003); and c) $\mathrm{R}^{2}$ was interpreted as the proportion of variability of the dependent variable explained by the model.

\section{Results and discussion}

3.1. Preliminary analysis to select, previously to the application of RSM optimization studies, the adequate ranges for the main MAE and UAE variables

The basic concept of the preliminary experiments, for MAE and UAE systems, is to assure that the experimental domain of the operating conditions, for the optimization procedure, will be properly defined to maximize the responses (Kala et al., 2016; Tiwari, 2015). It is well known that several variables can affect the extraction of compounds from natural sources (Bhuyan et al., 2015; Dahmoune et al., 2015; Routray and Orsat, 2012). However, different authors (Albuquerque et al., 2016; Heleno et al., 2016; Pinela et al., 2016b) are in agreement concerning the variables affecting the extraction responses in MAE and UAE systems, the main being identified as: $X_{1}(t, \min ), X_{2}\left(T,{ }^{\circ} \mathrm{C}\right.$ or $P, \mathrm{~W}$, respectively for MAE and UAE), $X_{3}(E t, \%)$ and $X_{4}(S / L, g / L)$. Therefore, to ensure a proper experimental domain, the relevant variables and ranges for MAE and UAE systems were selected based on the information gathered in the available bibliographical data and obtained by experimental results in one-variable-at-the-time-format. Results led to the following conclusions:

- The effect of $t$ plays one of the most important and critical roles. If samples are exposed at $t$ values lower or higher than the optimum one, compounds may not be properly extracted or, otherwise, degraded. In both extractions systems, the effect of $t$ is closely related to the $T$ (in case of MAE) and $P$ (in case of UAE). Generally, the effect of $T$ or $P$ interacts with $t$ positively (increasing the compounds extraction) or negatively (increasing the compounds degradation), compromising the achieved responses. In MAE the typical ranges for the $t$ and $T$ vary from small ranges, 0-160 s (Cardoso-Ugarte et al., 2014); 2-10 min, $25-55{ }^{\circ} \mathrm{C}$ (Thirugnanasambandham and Sivakumar, 2015) and to shorter $t$ and higher $T, 0-20 \mathrm{~min}, 60-180{ }^{\circ} \mathrm{C}$ (Pinela et al., 2016b). For the UAE, although the typical ranges are lower $t$ but with higher $P$ (5-15 min, 250-500 W, Heleno et al., 2016), there are cases in which lower $P$ and longer $t$ are used (15-45 min, 60-120 W, Maran et al., 2015).

- Regarding the type of solvent, and in the case of mixtures the used composition, authors also found important effects on the molecules to be extracted (Arnao et al., 2001; Sultana et al., 2009). Generally, the solvent extraction ability can be grouped in non-polar, polar aprotic and polar protic solvents (Huffman et al., 2012; Kislik, 2012). Water mixtures with polar solvents such as methanol, ethanol, acetone, among others, are the most commonly used in the extractions of natural compounds from plants (Prieto and Vázquez, 2014). Aqueous mixtures are preferable due to the range of the polarity degrees associated with the molecules to be extracted; it increases the microwave/ultrasound extraction efficiency, also allowing a better heat dissipation (Kala et al., 2016). In this sense, considering the principles of green chemistry, binary mixtures ethanol:water were selected as the extraction solvent. Therefore, the variable studied was the ethanol content in the ethanol:water mixture, which variation leads to significant differences (ranges from 0 to $100 \%$ were selected).

- Finally, the $S / L$ ratio interacts, at a very low extent, with the other system variables, but is very important parameter from the indus- 
trial point of view. It is well know that the contact surface of the sample with the extraction solvent will influences the efficiency of the extraction process (Kala et al., 2016; Tiwari, 2015). Lower $S / L$ ratios can facilitate the extraction process, but generates a high waste of solvent (10-30 g/mL, Maran et al., 2015; Thirugnanasambandham and Sivakumar, 2015), demanding its recovery and recycling. At an industrial scale, higher ratios need to be defined based on a compromise between process efficiency (more productive process) and minimal solvent consumption (more sustainable process) (5-45 g/L, Pinela et al., 2016).

Therefore, the final ranges selected for the five level CCCD of the RSM analysis for the four relevant variables (Fig. 1 and Table A1) were:

- For MAE process: $t(0-20 \mathrm{~min}), T\left(60-180{ }^{\circ} \mathrm{C}\right)$, Et $(0-100 \%)$ and $S / L$ $(5-45 \mathrm{~g} / \mathrm{L})$

- For UAE process: $t$ (2-22 min), $P(100-500 \mathrm{~W})$, Et (0-100\%) and $S / L$ (5-45 g/L).

The processing conditions were optimized based on several responses $\left(Y_{\text {Yield }}, Y_{\text {Colour }}, Y_{\text {Total }}, Y_{P 1}, Y_{P 2}, Y_{P 3}\right.$ and $\left.Y_{P 4}\right)$. The proposed RSM design (Fig. 1 and Table A1) reduces the number of experimental trials, which otherwise would imply 625 possible combinations (five levels of four independent variables), to be solved in 24 independent combinations and four replicates at the centre of the experimental design. The experimental results for the 28 runs are presented in Table 1.

\subsection{Optimization of the responses by RSM}

3.2.1. Development of theoretical response surface models and statistical verification

Fitting the models for the selected responses is crucial to elucidate, how precisely the RSM mathematical model can predict ideal variances. The models for each response were built by fitting the second-order polynomial model of Eq. (1) (independent variables in coded values) to the experimental values (Table 1) through nonlinear least-squares estimations. The resulting models are presented below.

For MAE:

When the extraction yield response was considered:

$$
\begin{aligned}
& Y_{\text {Yield }}^{M A E}= 38.97+0.64 x_{1}+6.25 x_{2}-3.94 x_{3}-2.24 x_{4}-0.91 x_{1}^{2}-0.66 x_{2}^{2} \\
& \quad-2.80 x_{4}^{2}+0.77 x_{3}^{2} \\
&-1.69 x_{2} x_{3}-1.22 x_{3} x_{4}
\end{aligned}
$$

When the betacyanin compounds (P1-4) and the total amount were considered:

$Y_{P 1}^{M A E}=1.0-0.04 x_{1}-0.45 x_{2}-0.33 x_{3}+0.15 x_{2}^{2}+0.09 x_{3}^{2}-0.38 x_{2} x_{3}$

$Y_{P 2}^{M A E}=1.1-0.08 x_{1}-1.12 x_{2}-0.94 x_{3}+0.43 x_{2}^{2}+0.34 x_{3}^{2}+1.08 x_{2} x_{3}$

$Y_{P 2}^{M A E}=1.1-0.08 x_{1}-1.12 x_{2}-0.94 x_{3}+0.43 x_{2}^{2}+0.34 x_{3}^{2}+1.08 x_{2} x_{3}$

$Y_{P 2}^{M A E}=1.1-0.08 x_{1}-1.12 x_{2}-0.94 x_{3}+0.43 x_{2}^{2}+0.34 x_{3}^{2}+1.08 x_{2} x_{3}$

$Y_{P 4}^{M A E}=1.0-0.13 x_{1}-0.83 x_{2}-0.65 x_{3}+0.13 x_{1}^{2}+0.28 x_{2}^{2}+0.21 x_{3}^{2}$ $+0.75 x_{2} x_{3}$

$Y_{\text {TOTAL }}^{M A E}=3.12-2.84 x_{2}-2.15 x_{3}-1.95 x_{4}+1.11 x_{2}^{2}+0.75 x_{3}^{2}+1.28 x_{4}^{2}$ $+2.51 x_{2} x_{3}$

When colour determination, based on spectrophotometric quantifi- cation, was considered:

$Y_{\text {Colour }}^{M A E}=13.91-7.30 x_{2}-4.09 x_{3}+1.75 x_{1}^{2}+1.74 x_{2}^{2}+1.18 x_{3}^{2}+3.35 x_{2} x_{3}$

For UAE:

When the extraction yield response was considered:

$Y_{\text {Yield }}^{\text {UAE }}=36.38+5.90 x_{1}+3.58 x_{2}-7.36 x_{3}-3.07 x_{4}+0.25 x_{1}^{2}-0.68 x_{2}^{2}$

$$
-1.04 x_{3}^{2}-1.37 x_{4}^{2}
$$

When the betacyanin compounds (P1-4) and the total amount were considered:

$Y_{P 1}^{U A E}=1.80+0.13 x_{1}+0.10 x_{2}-0.92 x_{3}-1.0 x_{4}+0.11 x_{3}^{2}+0.75 x_{4}^{2}$

$Y_{P 2}^{U A E}=2.40-2.68 x_{3}-0.80 x_{4}+0.40 x_{1}^{2}+0.37 x_{2}^{2}+0.93 x_{3}^{2}+0.70 x_{4}^{2}$

$Y_{P 3}^{U A E}=2.42+0.08 x_{1}-0.86 x_{3}-0.17 x_{1}^{2}-0.13 x_{2}^{2}$

$Y_{P 4}^{U A E}=2.46-1.60 x_{3}-0.42 x_{4}+0.19 x_{1}^{2}+0.18 x_{2}^{2}+0.68 x_{3}^{2}+0.51 x_{4}^{2}$

$Y_{\text {TOTAL }}^{\text {UAE }}=8.83+0.58 x_{1}-6.12 x_{3}-2.85 x_{4}+0.36 x_{1}^{2}+0.32 x_{2}^{2}+1.85 x_{3}^{2}$

$$
+2.19 x_{4}^{2}
$$

When the colour determination was considered:

$Y_{\text {Colour }}^{\text {UAE }}=20.83-4.00 x_{1}-3.93 x_{2}-4.61 x_{3}-4.41 x_{4}+1.28 x_{1}^{2}$

where $X_{1}(t, \min ), X_{2}\left(T,{ }^{\circ} \mathrm{C}\right.$ or $\left.P, \mathrm{~W}\right), X_{3}(E t, \%)$ and $X_{4}(S / L, g / L), Y$ is the response, sub-indices indicate the responses used and the superindices the technique applied. The mathematical models (Eqs. (2)-(8) for MAE and Eqs. (9)-(15) for UAE), and the parametric information present in Table 2, provides a complete summary of the effects caused by each of the involved variables defined for each extraction technique. In all cases, for both extraction methods, the linear effect was the most significant one, followed by the quadratic effect. Only the MAE procedure showed some interactive effects, consistently, between $X_{2}$ $\left(T,{ }^{\circ} \mathrm{C}\right)$ and $X_{3}(E t, \%)$ variables.

In all cases, the found statistical correlation coefficients $\left(\mathrm{R}^{2}\right)$, proved the good agreement between the experimental results and the predicted patterns, showing values higher than 0.82 . For the MAE system, the lowest value was 0.84 for the $Y_{P 2}$ response and the highest one was 0.97 for the $Y_{\text {Yield }}$ response. For the UAE method, the lowest value was 0.82 for the $Y_{\text {Colour }}$ response and the highest one was 0.97 for the $Y_{\text {Yield }}$ response.

3.2.2. Effects of the extraction variables used to evaluate the response criteria

The patterns observed for the extractions can be explained by means of the parametric values of the second-order polynomial models described in Eqs. (2)-(8) for MAE and Eqs. (9)-(15) for UAE, or can be illustrated by graphical representations. Figs. 2-4, Figs. A1 and A2 (Supplementary material) show the graphical results of the studied responses $\left(Y_{\text {Yield }}, Y_{\text {Colour }}, Y_{\text {Total }}, Y_{P 1}, Y_{P 2}, Y_{P 3}\right.$ and $\left.Y_{P 4}\right)$. For representation purposes, the variables excluded in each graph were positioned at the centre of their experimental domain. The obtained parametric fitting values are presented in Table 2 .

Fig. 2 shows the comparative matrix combination for the 3D surface responses of the $Y_{\text {Yield }}$ response for MAE and UAE processes. In the top diagonal part, the 3D surface responses of UAE are presented, while in the bottom diagonal, the ones presented are those derived from the MAE process. The effects can be summarized as follows:

- For MAE: The compound extraction increases at high $T$ and intermediate $t\left(180^{\circ} \mathrm{C}, 11.7 \mathrm{~min}\right)$ showing patterns with linear and quadratic effects. When $E t$ is higher than $20 \%$, the extraction yield starts to be compromised, a fact that can be associated with the 


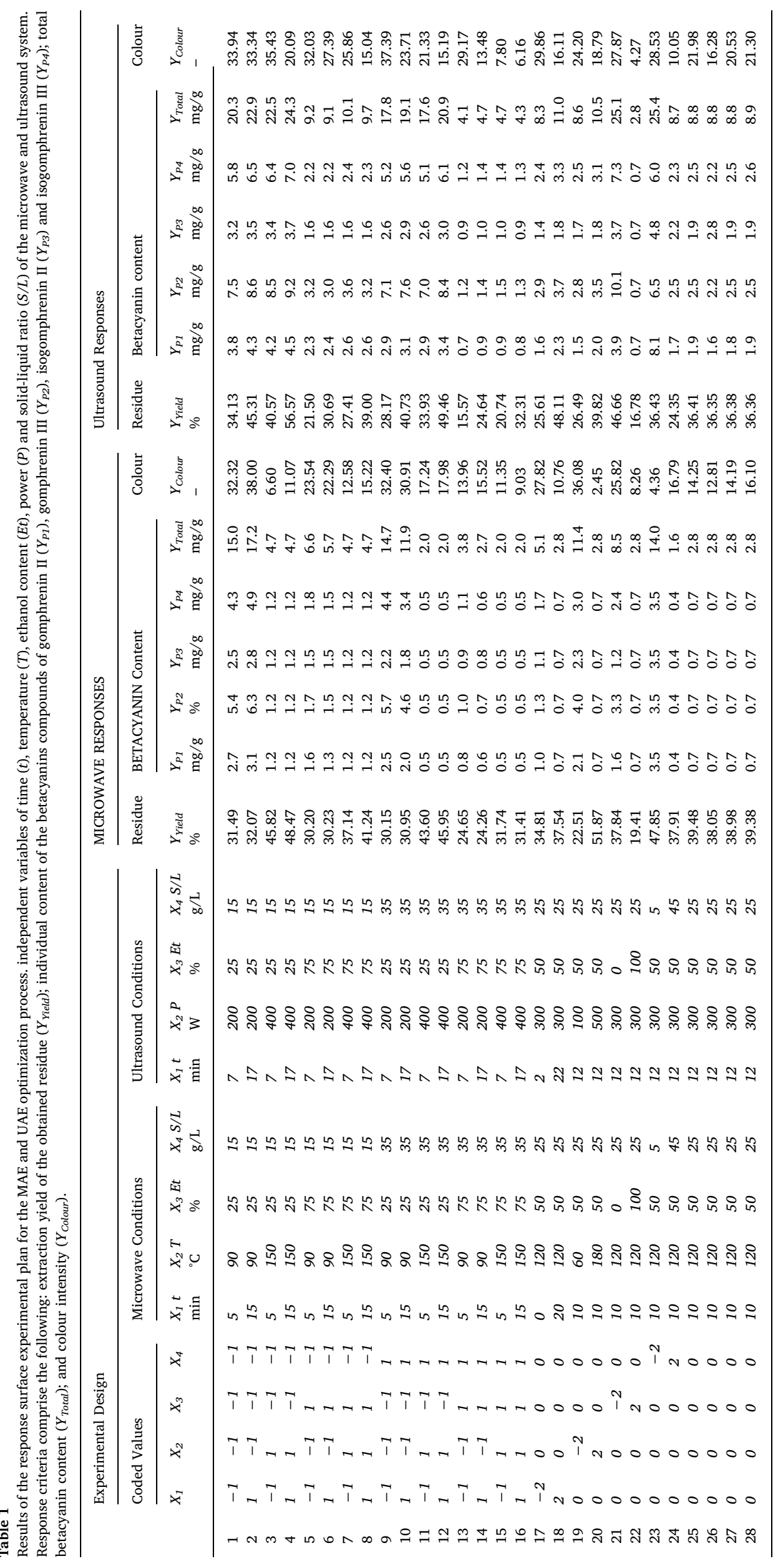




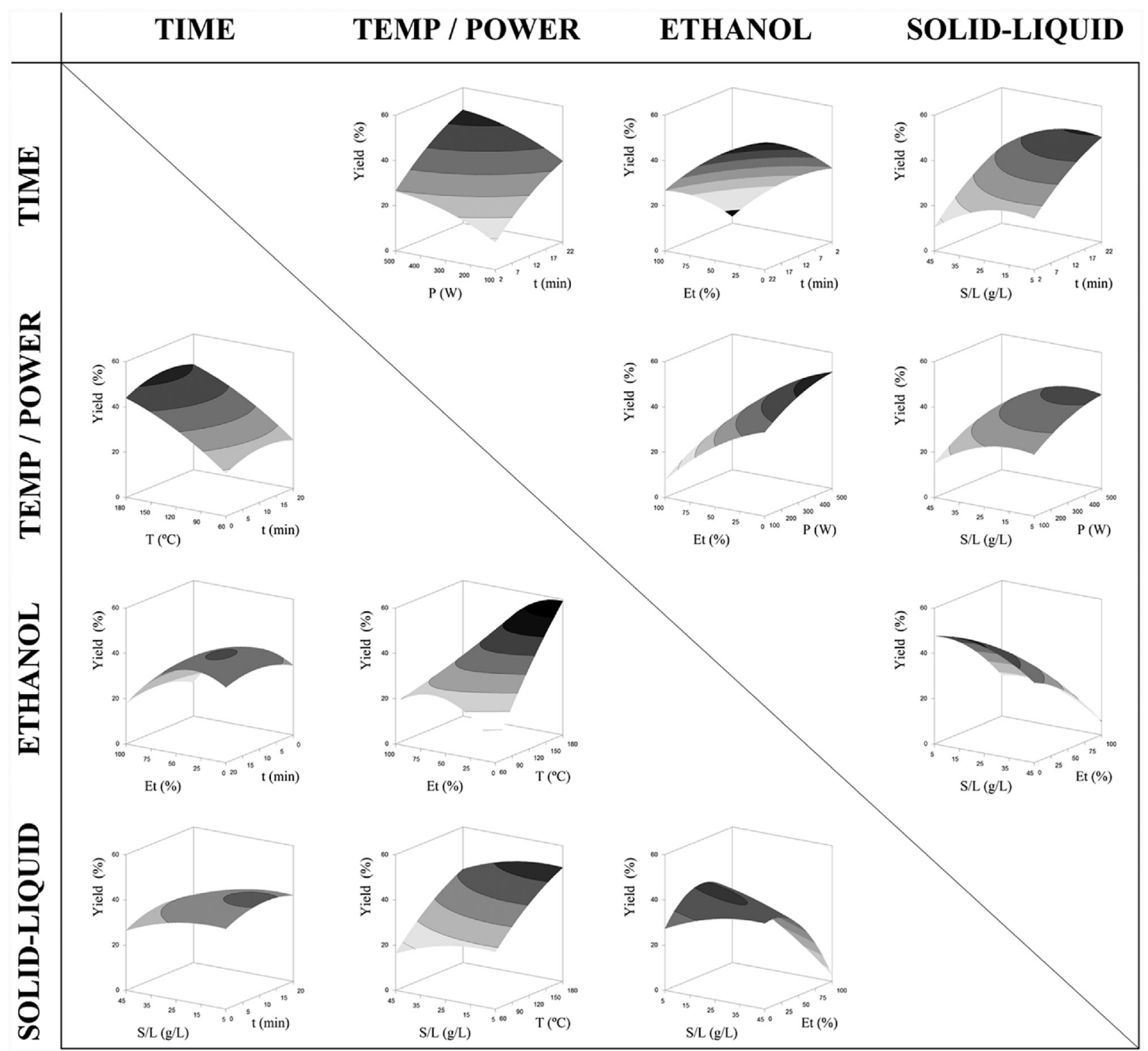

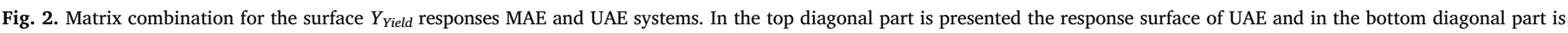

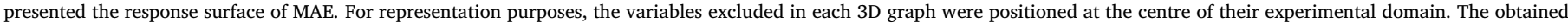

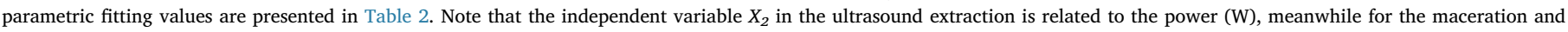
microwave extraction it is related with the temperature $\left({ }^{\circ} \mathrm{C}\right)$.

compounds polarity, which show higher affinity for hydrophilic environments. Regarding the $S / L$ ratio effect, low values favours optimal extraction yields $(5 \mathrm{~g} / \mathrm{L})$. The $E t$ and $S / L$ variables showed complex sceneries with linear, quadratic and interactive effects.

- For UAE: The optimal extraction responses are produced at intermediate $t$, high $P$, low $E t$ and low/medium values of $S / L(22 \mathrm{~min}$, $500 \mathrm{~W}, 0 \%, 13.7 \mathrm{~g} / \mathrm{L}$ respectively). Only linear and quadratic effects were found.

Fig. 3 shows the graphical matrix combination of the responses $Y_{\text {Total }}$ and $Y_{\text {Colour }}$. Each of the contour graphs represents the projection in $X Y$ plane of the theoretical three-dimensional response surface predicted with the second-order polynomial of Eq. (1). For the $Y_{\text {Total }}$ the response effects can be summarized as follows:

- For MAE: The $t$ variable did not show any relevant effect in the responses. This is a typical effect when analysing the response of various compounds due to the dissimilar time response effects of each one. The optimal extraction responses are produced at high $T$, low percentage of $E t$ and low values of $S / L\left(180{ }^{\circ} \mathrm{C}, 28.2 \%, 5 \mathrm{~g} / \mathrm{L}\right.$, respectively). Linear and quadratic effects, produced by models, governed the response. Only the variables $T$ and Et showed interactive effects.

- UAE: The optimal extraction responses are produced at higher $t$, higher $P$, absence of $E t$ and medium/low values of $S / L$ (22 min, $500 \mathrm{~W}, 0 \%, 13.7 \mathrm{~g} / \mathrm{L}$, respectively). Only linear and quadratic effects were found.

For $Y_{\text {Colour }}$ the response effects can be summarized as follows:

- For MAE: Simple response scenarios are found, in which only some linear and quadratic effects are found. The optimal extraction responses are produced at medium low $t$, low $T$, absence of $E t$ and low values of $S / L\left(8 \mathrm{~min}, 60^{\circ} \mathrm{C}, 0 \%, 5 \mathrm{~g} / \mathrm{L}\right.$, respectively).

- For UAE: The optimal extraction responses are produced at short $t$, low $P$, absence of $E t$ and low values of $S / L(2 \mathrm{~min}, 100 \mathrm{~W}, 0 \%, 5 \mathrm{~g} / \mathrm{L}$, 
$Y_{\text {Total }}$
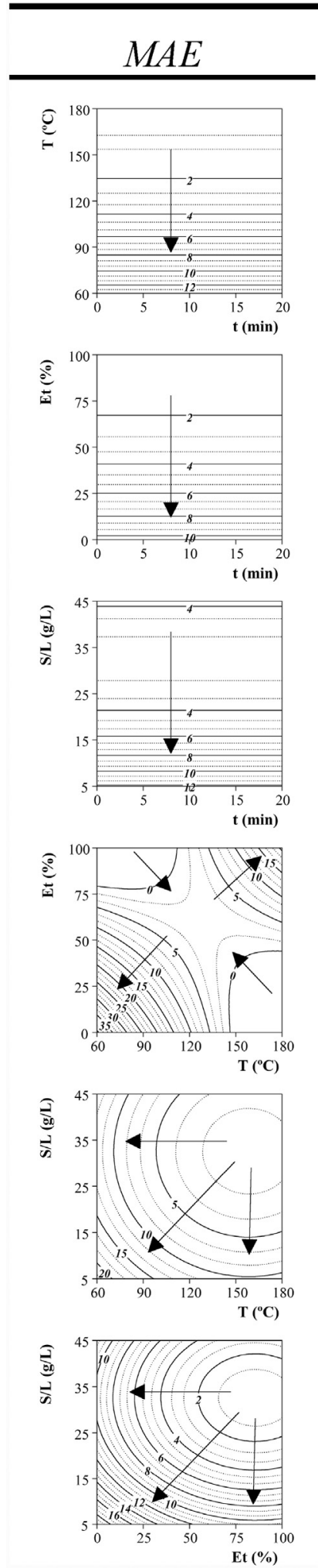

$Y_{\text {Colour }}$
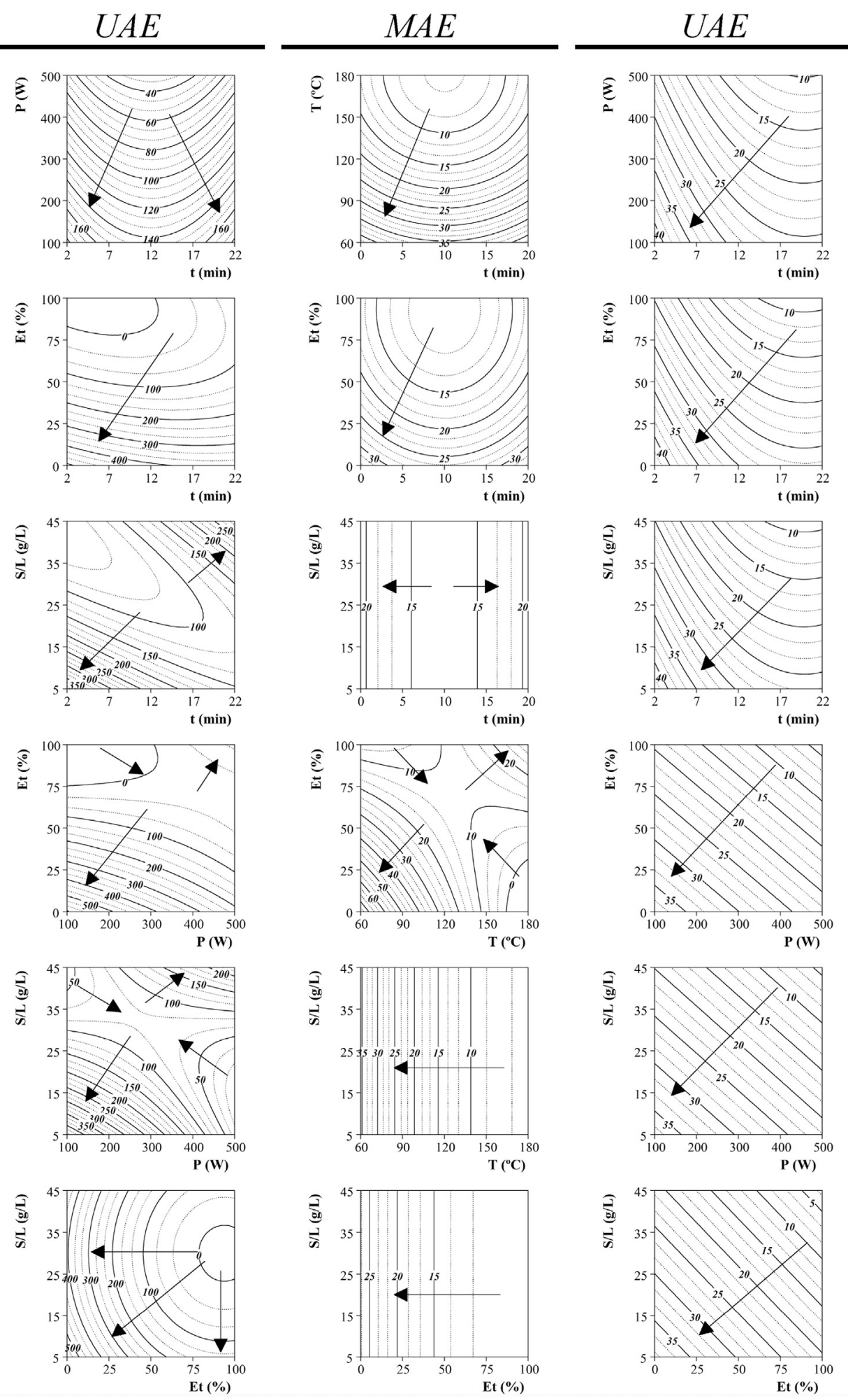

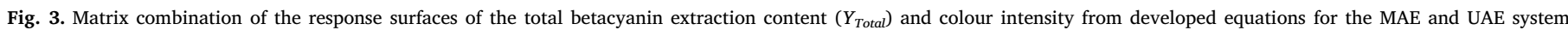

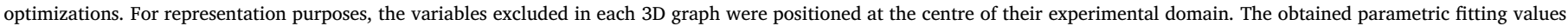
are presented in Table 3.

respectively).

Finally, Figs. A1 and A2 (Supplementary material) show the contour graphs of the individual betacyanin compounds content $\left(Y_{P 1}-Y_{P 4}\right)$ for
MAE and UAE systems, respectively. The response effects can be summarized as follows:

- For MAE: The linear and quadratic effects are once again the 
MAE RESPONSES
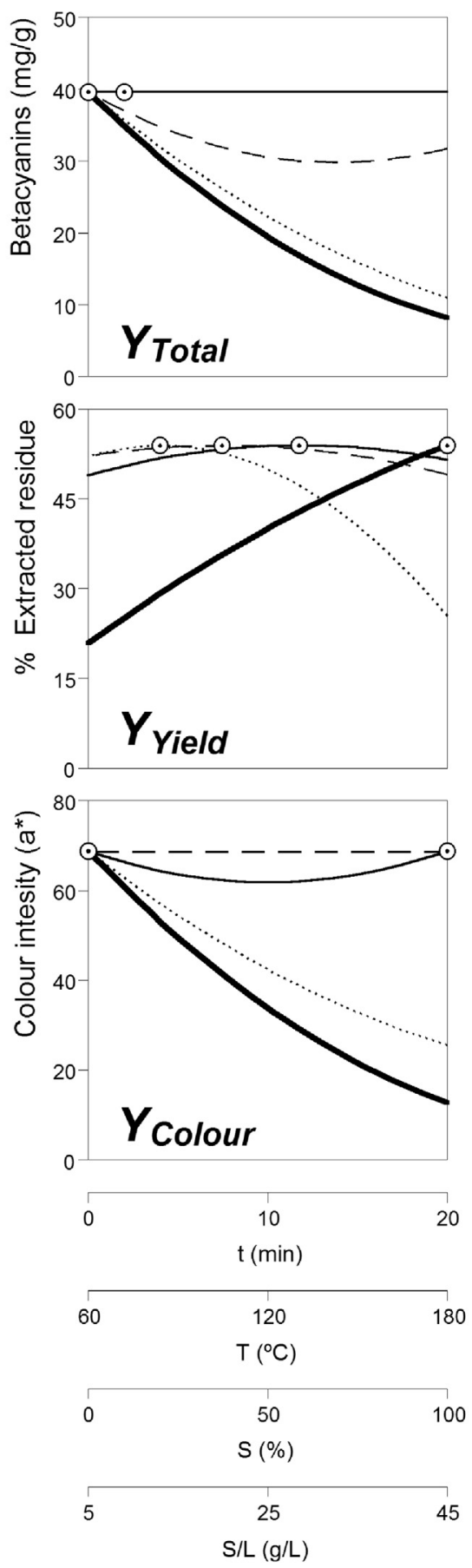

\section{UAE RESPONSES}
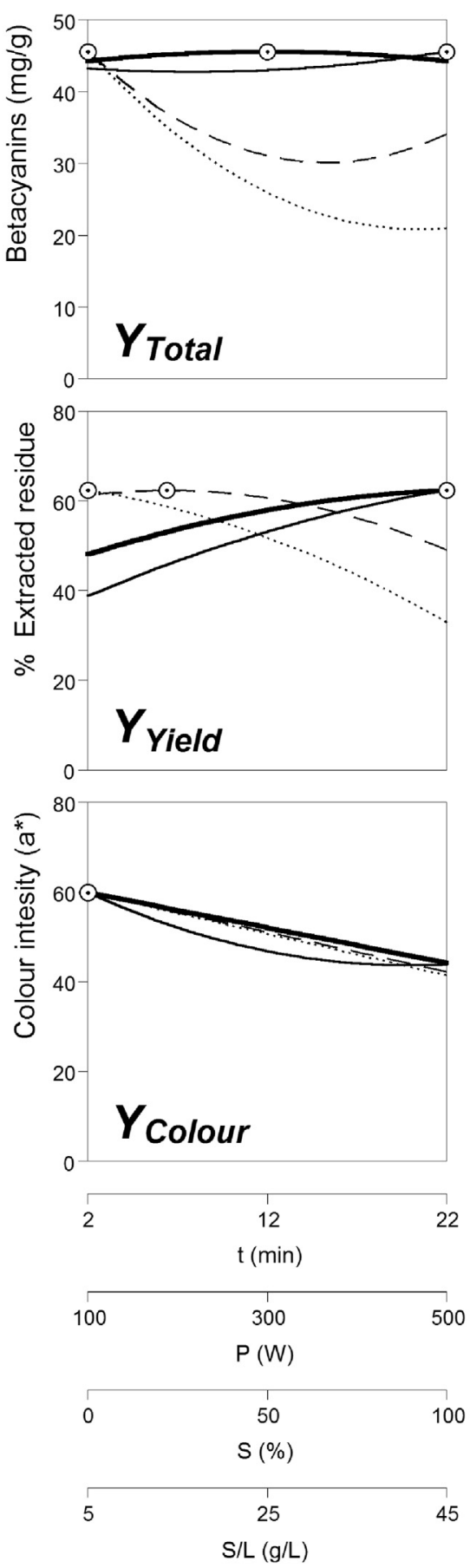

$\operatorname{Et}(\%) \quad-\quad S / L(\mathrm{~g} / \mathrm{L})$

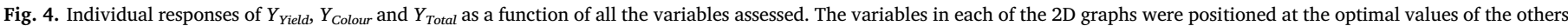

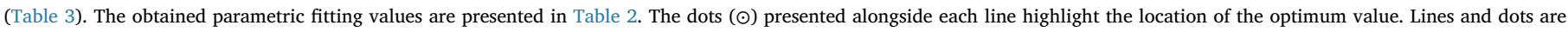

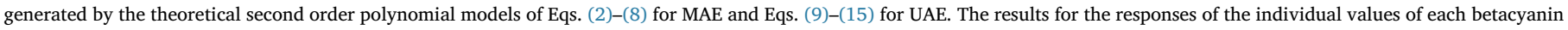
compound identified $\left(Y_{P 1}, Y_{P 2}, Y_{P 3}\right.$ and $\left.Y_{P 4}\right)$ were excluded due to their pattern similarities with the $Y_{\text {Total }}$.

predominant effect for all compounds content $\left(Y_{P 1}\right.$, to $\left.Y_{P 4}\right)$. The optimal extraction response is the same for all the compounds and produced at short $t$, low $T$, absence of $E t$ and low values of $S / L$ ( $8 \mathrm{~min}, 60^{\circ} \mathrm{C}, 0 \%, 5 \mathrm{~g} / \mathrm{L}$, respectively).

- For UAE: This methodology showed a simpler response than MAE. It was noted that the response $Y_{P 3}$ showed different optimum values compared with the other applied response criteria. Therefore, the optimal extraction response for $Y_{P 1}, Y_{P 2}$ and $Y_{P 4}$ are produced at higher $t$ and $T$, absence of $E t$, and low values of $S / L(22 \mathrm{~min}, 500 \mathrm{~W}$, $0 \%, 5 \mathrm{~g} / \mathrm{L}$, respectively), while $Y_{P 3}$ produce the optimal extraction response at medium values of $t$ and $T$, absence of $E t$, and low values of $S / L$ (13 min, 300, 0\%, $5 \mathrm{~g} / \mathrm{L}$, respectively). 
Table 2

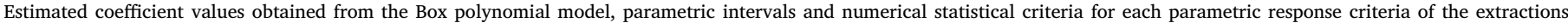

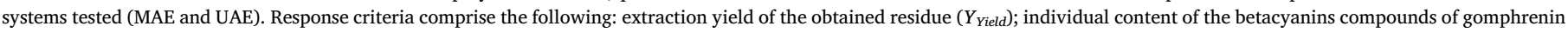
II $\left(Y_{P 1}\right)$, gomphrenin III $\left(Y_{P 2}\right)$, isogomphrenin II $\left(Y_{P 3}\right)$ and isogomphrenin III $\left(Y_{P 4}\right)$; total betacyanin content $\left(Y_{\text {Total }}\right)$; and colour intensity $\left(Y_{\text {Colour }}\right)$.

\begin{tabular}{|c|c|c|c|c|c|c|c|c|}
\hline \multirow[t]{2}{*}{ Parameters } & & \multirow{2}{*}{$\begin{array}{l}\text { Residue } \\
Y_{\text {Yield }}\end{array}$} & \multicolumn{5}{|c|}{ Betacyanin Content } & \multirow{2}{*}{$\begin{array}{l}\text { Colour } \\
Y_{\text {Colour }}\end{array}$} \\
\hline & & & $Y_{P 1}$ & $Y_{P 2}$ & $Y_{P 3}$ & $Y_{P 4}$ & $Y_{\text {Total }}$ & \\
\hline \multicolumn{9}{|c|}{ Microwave Asisted Extraction } \\
\hline Intercept & $\mathrm{b}_{0}$ & $38.97 \pm 1.05$ & $0.99 \pm 0.35$ & $1.11 \pm 0.42$ & $1.01 \pm 0.34$ & $1.01 \pm 0.46$ & $3.12 \pm 0.85$ & $13.91 \pm 2.87$ \\
\hline \multirow[t]{4}{*}{ Linear effect } & $\mathrm{b}_{1}$ & $0.64 \pm 0.61$ & $-0.04 \pm 0.27$ & $-0.08 \pm 0.03$ & $-0.04 \pm 0.00$ & $-0.13 \pm 0.11$ & ns & ns \\
\hline & $\mathrm{b}_{2}$ & $6.25 \pm 0.61$ & $-0.45 \pm 0.27$ & $-1.12 \pm 0.32$ & $-0.44 \pm 0.26$ & $-0.83 \pm 0.31$ & $-2.84 \pm 0.56$ & $-7.30 \pm 1.89$ \\
\hline & $\mathrm{b}_{3}$ & $-3.94 \pm 0.61$ & $-0.33 \pm 0.27$ & $-0.94 \pm 0.32$ & $-0.24 \pm 0.06$ & $-0.65 \pm 0.31$ & $-2.15 \pm 0.56$ & $-4.09 \pm 1.89$ \\
\hline & $\mathrm{b}_{4}$ & $-2.24 \pm 0.61$ & ns & $\mathrm{ns}$ & $\mathrm{ns}$ & ns & $-1.95 \pm 0.56$ & $\mathrm{~ns}$ \\
\hline \multirow{4}{*}{ Quadratic effect } & $b_{11}$ & $-0.91 \pm 0.55$ & ns & ns & $0.02 \pm 0.00$ & $0.13 \pm 0.11$ & $\mathrm{~ns}$ & $1.75 \pm 1.70$ \\
\hline & $\mathrm{b}_{22}$ & $-0.66 \pm 0.55$ & $0.15 \pm 0.24$ & $0.43 \pm 0.29$ & $0.17 \pm 0.02$ & $0.28 \pm 0.27$ & $1.11 \pm 0.50$ & $1.74 \pm 1.70$ \\
\hline & $b_{33}$ & $-2.80 \pm 0.55$ & $0.09 \pm 0.24$ & $0.34 \pm 0.29$ & $\mathrm{~ns}$ & $0.21 \pm 0.11$ & $0.75 \pm 0.50$ & $1.18 \pm 0.79$ \\
\hline & $\mathrm{b}_{44}$ & $0.77 \pm 0.55$ & ns & ns & ns & ns & $1.28 \pm 0.50$ & $\mathrm{~ns}$ \\
\hline \multirow[t]{6}{*}{ Interactive effect } & $\mathrm{b}_{12}$ & ns & ns & ns & ns & ns & ns & ns \\
\hline & $\mathrm{b}_{13}$ & ns & ns & ns & ns & ns & ns & ns \\
\hline & $\mathrm{b}_{14}$ & ns & ns & ns & ns & ns & ns & ns \\
\hline & $\mathrm{b}_{23}$ & $-1.69 \pm 0.74$ & $0.38 \pm 0.33$ & $1.08 \pm 0.39$ & $0.30 \pm 0.11$ & $0.75 \pm 0.37$ & $2.51 \pm 0.69$ & $3.35 \pm 2.31$ \\
\hline & $\mathrm{b}_{24}$ & ns & ns & $\mathrm{ns}$ & $\mathrm{ns}$ & ns & ns & ns \\
\hline & $\mathrm{b}_{34}$ & $-1.22 \pm 0.74$ & ns & ns & $\mathrm{ns}$ & ns & ns & ns \\
\hline Statistics $\left(\mathrm{R}^{2}\right)$ & & 0.9766 & 0.9116 & 0.8456 & 0.8621 & 0.9588 & 0.9321 & 0.8975 \\
\hline \multicolumn{9}{|c|}{ Ultrasound Asisted Extraction } \\
\hline Intercept & $\mathrm{b}_{0}$ & $36.38 \pm 0.85$ & $1.80 \pm 0.25$ & $2.40 \pm 0.50$ & $2.42 \pm 0.33$ & $2.46 \pm 0.50$ & $8.83 \pm 1.16$ & $20.83 \pm 1.90$ \\
\hline \multirow[t]{4}{*}{ Linear effect } & $\mathrm{b}_{1}$ & $5.90 \pm 0.49$ & $0.13 \pm 0.06$ & ns & $0.08 \pm 0.03$ & ns & $0.58 \pm 0.27$ & $-4.00 \pm 1.74$ \\
\hline & $\mathrm{b}_{2}$ & $3.58 \pm 0.49$ & $0.10 \pm 0.06$ & ns & $\mathrm{ns}$ & ns & ns & $-3.93 \pm 1.74$ \\
\hline & $\mathrm{b}_{3}$ & $-7.36 \pm 0.49$ & $-0.92 \pm 0.19$ & $-2.68 \pm 0.29$ & $-0.86 \pm 0.37$ & $-1.60 \pm 0.29$ & $-6.12 \pm 0.67$ & $-4.61 \pm 1.74$ \\
\hline & $\mathrm{b}_{4}$ & $-3.07 \pm 0.49$ & $-1.00 \pm 0.19$ & $-0.80 \pm 0.29$ & $\mathrm{~ns}$ & $-0.42 \pm 0.29$ & $-2.85 \pm 0.67$ & $-4.41 \pm 1.74$ \\
\hline \multirow[t]{4}{*}{ Quadratic effect } & $b_{11}$ & $0.25 \pm 0.21$ & ns & $0.40 \pm 0.26$ & $-0.17 \pm 0.03$ & $0.19 \pm 0.11$ & $0.36 \pm 0.27$ & $1.28 \pm 1.55$ \\
\hline & $\mathrm{b}_{22}$ & $-0.68 \pm 0.44$ & ns & $0.37 \pm 0.26$ & $-0.13 \pm 0.03$ & $0.18 \pm 0.11$ & $0.32 \pm 0.27$ & ns \\
\hline & $b_{33}$ & $-1.04 \pm 0.44$ & $0.11 \pm 0.03$ & $0.93 \pm 0.26$ & $\mathrm{~ns}$ & $0.68 \pm 0.26$ & $1.85 \pm 0.60$ & ns \\
\hline & $\mathrm{b}_{44}$ & $-1.37 \pm 0.44$ & $0.75 \pm 0.17$ & $0.70 \pm 0.26$ & ns & $0.51 \pm 0.26$ & $2.19 \pm 0.60$ & ns \\
\hline \multirow[t]{6}{*}{ Interactive effect } & $\mathrm{b}_{12}$ & $\mathrm{~ns}$ & ns & ns & ns & ns & ns & ns \\
\hline & $b_{13}$ & ns & ns & ns & ns & ns & ns & ns \\
\hline & $\mathrm{b}_{14}$ & $\mathrm{~ns}$ & $\mathrm{~ns}$ & ns & ns & ns & ns & ns \\
\hline & $\mathrm{b}_{23}$ & ns & ns & ns & ns & ns & ns & ns \\
\hline & $\mathrm{b}_{24}$ & $\mathrm{~ns}$ & ns & ns & ns & ns & ns & ns \\
\hline & $b_{34}$ & $\mathrm{~ns}$ & ns & ns & $\mathrm{ns}$ & ns & ns & ns \\
\hline Statistics $\left(\mathrm{R}^{2}\right)$ & & 0.9689 & 0.9206 & 0.9508 & 0.8639 & 0.9224 & 0.9588 & 0.8256 \\
\hline
\end{tabular}

\subsection{Optimal extraction conditions for maximizing the responses criteria}

Although the effects described above provided a guiding range of conditions, where the responses are maximized, optimal values can be achieved using a simple method tool to solve non-linear problems (Heleno et al., 2016; Pinela et al., 2016a). The results of the application of this simple procedure are presented in Table 3 , in which the operating conditions that maximize each of the responses, in individual and global terms, are presented. Additionally, Fig. 4 summarizes the information derived from the mathematical equations, presenting the 2D graphs as a function of all the accessed variables. The results for the responses of the individual values of each identified betacyanin compound $\left(Y_{P 1}, Y_{P 2}, Y_{P 3}\right.$ and $\left.Y_{P 4}\right)$ were excluded due to their pattern similarities with the $Y_{\text {Total }}$. The variables in each of the 2D graphs were positioned at the optimal values of the others (Table 3). If the optimal individual conditions achieved are not found in absolute terms and they are relative optimums when the optimal value may be outside of the experimental range studied, the conditions that maximize the responses are marked (*). The information can be summarized as follows (first part of Table 3):

- The maximum response values and optimal conditions for the MAE technique were: the $Y_{\text {Yield }}$ with $58.6 \pm 1.5 \%$ at the optimal conditions of $11.7 \mathrm{~min},\left(^{*}\right) 180{ }^{\circ} \mathrm{C}, 28.2 \%$ of ethanol and $\left(^{*}\right) 5 \mathrm{~g} / \mathrm{L}$; the $Y_{\text {Total }}$ with $39.6 \pm 1.8 \mathrm{mg} / \mathrm{g}$ at the optimal conditions of $\left(^{*}\right) 8 \mathrm{~min}$, (*) $60{ }^{\circ} \mathrm{C}, 0 \%$ of ethanol and (*) $5 \mathrm{~g} / \mathrm{L}$; the $Y_{\text {Colour }}$ with $68.8 \pm 2.2$ at the optimal conditions of $11.7 \mathrm{~min},(*) 60^{\circ} \mathrm{C}, 0 \%$ of ethanol and (*) $5 \mathrm{~g} / \mathrm{L}$.
- The maximum response values and optimal conditions for the UAE technique were: the $Y_{\text {Yield }}$ with $65.9 \pm 4.8 \%$ at the optimal conditions of (*) $22.0 \mathrm{~min},\left(^{*}\right) 500 \mathrm{~W}, 0 \%$ of ethanol and $13.7 \mathrm{~g} / \mathrm{L}$; the $Y_{\text {Total }}$ with $46.9 \pm 4.8 \mathrm{mg} / \mathrm{g}$ at the optimal conditions of (*) $22 \mathrm{~min}, 300 \mathrm{~W}, 0 \%$ of ethanol and $\left(^{*}\right) 5 \mathrm{~g} / \mathrm{L}$; the $Y_{\text {Colour }}$ with $59.9 \pm 1.6$ at the optimal conditions of (*) $2 \mathrm{~min}, 100 \mathrm{~W}, 0 \%$ of ethanol and (*) $5 \mathrm{~g} / \mathrm{L}$.

When combining, the information produced from all response criteriás $\left(Y_{\text {Yield }}, Y_{\text {Colour }}, Y_{\text {Total }}, Y_{P 1}, Y_{P 2}, Y_{P 3}\right.$ and $\left.Y_{P 4}\right)$, the complete behaviour of each relevant variable influencing the responses is defined in global terms. The global optimizing results are presented in the second part of Table 3 and summarized below:

- For MAE response: the optimal global conditions were at (*) $20 \mathrm{~min}$, (*) $60{ }^{\circ} \mathrm{C}, 0 \%$ and $\left(^{*}\right) 5 \mathrm{~g} / \mathrm{L}$, producing $8.0 \pm 0.6 \%$ ( $Y_{\text {Yield }}$ ), $39.6 \pm 2.9 \mathrm{mg} / \mathrm{g}\left(Y_{\text {Total }}\right)$ and $68.7 \pm 6.2\left(Y_{\text {Colour }}\right)$. Regarding the responses of the compounds $\mathrm{P} 1$ to $\mathrm{P} 4$ the results in $\mathrm{mg} / \mathrm{g}$ were $4.9 \pm 1.1,12.4 \pm 1.5,4.2 \pm 0.9$ and $9.2 \pm 1.1$, respectively.

- For UAE response: the optimal global conditions were at (*) $22 \mathrm{~min}$, $257.8 \mathrm{~W}, 0 \%$ and $(*) 5 \mathrm{~g} / \mathrm{L}$, producing $55.2 \pm 5.1 \%$ (Y Yield $_{\text {) }}$, $45.5 \pm 6.2 \mathrm{mg} / \mathrm{g}\left(Y_{\text {Total }}\right)$ and $37.6 \pm 2.5$ ( $\left.Y_{\text {Colour }}\right)$. Regarding the responses of the compounds $\mathrm{P} 1$ to $\mathrm{P} 4$ the results in $\mathrm{mg} / \mathrm{g}$ were $9.3 \pm 1.4,17.5 \pm 1.1,3.6 \pm 0.4$ and $12.1 \pm 1.2$, respectively.

The global optimal conditions found were experimentally tested to confirm the accuracy of the presented results. Comparing the results of the extraction efficiencies among the techniques, UAE gave signifi- 
Table 3

Operating conditions that maximize the extraction of betacyanin from Gomphrena globosa and optimal response values for the parametric response criteria. Response criteria comprise the following: extraction yield of the obtained residue $\left(Y_{\text {Yield }}\right)$; individual content of the betacyanins compounds of gomphrenin II $\left(Y_{P 1}\right)$, gomphrenin III $\left(Y_{P 2}\right)$, isogomphrenin II $\left(Y_{P 3}\right)$ and isogomphrenin III $\left(Y_{P 4}\right)$; total betacyanin content $\left(Y_{\text {Total }}\right)$; and colour intensity $\left(Y_{\text {Colour }}\right)$. Note that the independent variable $X_{2}$ in the ultrasound extraction is related to the power (W), meanwhile for the maceration and microwave extraction is related to temperature $\left({ }^{\circ} \mathrm{C}\right)$.

Optimal Extraction Conditions Response Optimum

$$
\begin{array}{llll}
X_{1}: t(\min ) & X_{2}: T\left({ }^{\circ} \mathrm{C}\right) \text { or } & X_{3}: E t(\%) & X_{4}: S / L \\
& P(\mathrm{~W}) & & (\mathrm{g} / \mathrm{L})
\end{array}
$$

\begin{tabular}{|c|c|c|c|c|c|}
\hline \multicolumn{6}{|c|}{ Individual Optimal Responses } \\
\hline \multicolumn{6}{|c|}{ Microwave Assisted Extraction (MAE) } \\
\hline$Y_{\text {Yield }}$ & 11.7 & 180.0 & 28.2 & 5.0 & $58.6 \pm 1.5 \%$ \\
\hline$Y_{\text {Total }}$ & 8.0 & 60.0 & 0.0 & 5.0 & $39.6 \pm 1.8 \mathrm{mg} / \mathrm{g}$ \\
\hline$Y_{\text {Colour }}$ & 8.0 & 60.0 & 0.0 & 5.0 & $68.8 \pm 2.2$ \\
\hline$Y_{P 1}$ & 8.0 & 60.0 & 0.0 & 5.0 & $5.1 \pm 0.9 \mathrm{mg} / \mathrm{g}$ \\
\hline$Y_{P 2}$ & 8.0 & 60.0 & 0.0 & 5.0 & $12.7 \pm 1.1 \mathrm{mg} / \mathrm{g}$ \\
\hline$Y_{P 3}$ & 8.0 & 60.0 & 0.0 & 5.0 & $4.4 \pm 0.7 \mathrm{mg} / \mathrm{g}$ \\
\hline$Y_{P 4}$ & 8.0 & 60.0 & 0.0 & 5.0 & $9.5 \pm 0.6 \mathrm{mg} / \mathrm{g}$ \\
\hline \multicolumn{6}{|c|}{ Ultrasound Assisted Extraction (UAE) } \\
\hline$Y_{\text {Yield }}$ & 22.0 & 500.0 & 0.0 & 13.7 & $65.9 \pm 4.8 \%$ \\
\hline$Y_{\text {Total }}$ & 22.0 & 300.0 & 0.0 & 5.0 & $46.9 \pm 4.8 \mathrm{mg} / \mathrm{g}$ \\
\hline$Y_{\text {Colour }}$ & 2.0 & 100.0 & 0.0 & 5.0 & $59.9 \pm 1.6$ \\
\hline$Y_{P 1}$ & 22.0 & 500.0 & 0.0 & 5.0 & $9.5 \pm 1.1 \mathrm{mg} / \mathrm{g}$ \\
\hline$Y_{P 2}$ & 22.0 & 500.0 & 0.0 & 5.0 & $19.0 \pm 3.3 \mathrm{mg} / \mathrm{g}$ \\
\hline$Y_{P 3}$ & 13.2 & 300.0 & 0.0 & 5.0 & $4.2 \pm 0.7 \mathrm{mg} / \mathrm{g}$ \\
\hline$Y_{P 4}$ & 22.0 & 500.0 & 0.0 & 5.0 & $12.7 \pm 2.6 \mathrm{mg} / \mathrm{g}$ \\
\hline \multicolumn{6}{|c|}{ Global Optimal Responses } \\
\hline \multicolumn{6}{|c|}{ Microwave Assisted Extraction (MAE) } \\
\hline$Y_{\text {Yield }}$ & 20.0 & 60.0 & 0.0 & 5.0 & $8.0 \pm 0.6 \%$ \\
\hline$Y_{\text {Total }}$ & & & & & $39.6 \pm 2.9 \mathrm{mg} / \mathrm{g}$ \\
\hline$Y_{\text {Colour }}$ & & & & & $68.7 \pm 6.2$ \\
\hline$Y_{P 1}$ & & & & & $4.9 \pm 1.1 \mathrm{mg} / \mathrm{g}$ \\
\hline$Y_{P 2}$ & & & & & $12.4 \pm 1.5 \mathrm{mg} / \mathrm{g}$ \\
\hline$Y_{P 3}$ & & & & & $4.2 \pm 0.9 \mathrm{mg} / \mathrm{g}$ \\
\hline$Y_{P 4}$ & & & & & $9.2 \pm 1.1 \mathrm{mg} / \mathrm{g}$ \\
\hline \multicolumn{6}{|c|}{ Ultrasound Assisted Extraction (UAE) } \\
\hline$Y_{\text {Yield }}$ & 22.0 & 257.8 & 0.0 & 5.0 & $55.2 \pm 5.1 \%$ \\
\hline$Y_{\text {Total }}$ & & & & & $45.5 \pm 6.2 \mathrm{mg} / \mathrm{g}$ \\
\hline$Y_{\text {Colour }}$ & & & & & $37.6 \pm 2.5$ \\
\hline$Y_{P 1}$ & & & & & $9.3 \pm 1.4 \mathrm{mg} / \mathrm{g}$ \\
\hline$Y_{P 2}$ & & & & & $17.5 \pm 1.1 \mathrm{mg} / \mathrm{g}$ \\
\hline$Y_{P 3}$ & & & & & $3.6 \pm 0.4 \mathrm{mg} / \mathrm{g}$ \\
\hline$Y_{P 4}$ & & & & & $12.1 \pm 1.2 \mathrm{mg} / \mathrm{g}$ \\
\hline
\end{tabular}

cantly higher values than MAE. Regarding the extraction time, MAE was a faster extraction method. Although water is a polar solvent with greater interest in green processes, ethanol has a hydroxyl group and dissolves many ionic compounds, but also has a non-polar end, which will contribute to dissolve non-polar substances. However, in the extraction of betacyanin compounds, in terms of colour intensity $\left(Y_{\text {Colour }}\right)$, or content $\left(Y_{\text {Total }}, Y_{P 1}, Y_{P 2}, Y_{P 3}\right.$ and $\left.Y_{P 4}\right)$, the presence of ethanol did not improve their final optimal values. The optimal conditions of the binary interactions of ethanol-water mixture were found generally preferable in pure water solutions. About the $S / L$ factor, a broad range was tested, finding that lower values lead to an enhanced extraction yield, but also contributed to a significant waste of solvent. A higher $S / L$ will result in lower extraction yields but in a better rationalization of raw materials consumption.

3.4. Comparing the betacyanin extraction results from $G$. globosa obtained by MAE and UAE with results from literature using other plant source materials

For beta vulgaris, one of the best source of betacyanins, different authors have shown optimal extraction values using different variable conditions: $0.26-1.99 \mathrm{mg} / \mathrm{g} \mathrm{dw}$ (Vulić et al., 2012); 2.81-5.38 mg/g dw (Stagnari et al., 2014); and $9.6 \mathrm{mg} / \mathrm{g} \mathrm{dw}$ (Pavlov and Bley, 2006). From the Amaranthaceae family (Li et al., 2015; Silva et al., 2012), the Amaranthus hypochondriacus $\mathrm{L}$. showed a maximum value of $16.90 \mathrm{mg} /$ $\mathrm{g} \mathrm{dw}$, meanwhile the Amaranthus caudatus L. showed $20.93 \mathrm{mg} / \mathrm{g} \mathrm{dw}$. Using paper flower (Bougainvillea glabra Choisy) as a material source, Maran et al., 2015 reported an optimum response of $1.76 \mathrm{mg} / \mathrm{g} \mathrm{dw}$. Even when a optimization procedure is applied using RSM with beetroot as a source of betacyanin compounds (Cardoso-Ugarte et al., 2014), the best results found were $1.3 \mathrm{mg} / \mathrm{g}$ of freeze-dried beet root. For dragon fruit (Hylocereus polyrhizus (Weber) Britton \& Rose) values of $1.8 \mathrm{mg} / \mathrm{g} \mathrm{dw}$ were found (Thirugnanasambandham and Sivakumar, 2015). All of them are far beyond those produced by $G$. globosa in which it was possible to obtain 39.6 and $46.9 \mathrm{mg} / \mathrm{g}$ (expressed as plant $\mathrm{dw}$ ) with MAE and UAE, respectively.

In general, UAE or MAE modern techniques, showed better responses than traditional ones (e.g. dynamic maceration). Although it was expected to extract higher amounts of betacyanin compounds, the working variables $t$ and $E t$ showed lower optimal values than usual, making these techniques an asset for industry.

\section{Conclusions}

When compared with traditional techniques, MAE and UAE, are powerful and modern extraction procedures that proved to be efficient for betacyanins extraction, with the advantage of reducing the extraction time. The combined effects of the independent variables $t, T$ or $P, E t$ and $S / L$ on the extraction of couloring compounds from $G$. globosa were optimized using a five-level full factorial design of 24 combinations and four replicates at the centre to maximize the responses. The response criteriás were the extract yield $\left(Y_{\text {Yield }}\right)$, the analytical colour parameter $a^{*}$ ( $\left.Y_{\text {Colour }}\right)$, the quantification of the total sum of the betacyanin compounds by HPLC-DAD analysis $\left(Y_{\text {Total }}\right)$ and the quantification of the individual betacyanin compounds P1 to P4 $\left(Y_{P 1}\right.$ to $\left.Y_{P 4}\right)$. The experimental domain was successfully implemented for MAE and UAE optimization using RSM. The MAE and UAE conditions were optimized for each response, as well as for the combined responses. Under the global optimum conditions for $\operatorname{MAE}\left(t=8 \mathrm{~min}, T=60{ }^{\circ} \mathrm{C}, E t=0 \%\right.$, and $S / L=5 \mathrm{~g} / \mathrm{L}$ ), the optimal response value was $39.6 \pm 1.8 \mathrm{mg} / \mathrm{g}$; for UAE ( $t=22 \mathrm{~min}, P=500 \mathrm{~W}, E t=0 \%$, and $S / L=5 \mathrm{~g} / \mathrm{L}$ ) being in this case the optimal response value of $46.9 \pm 4.8 \mathrm{mg} / \mathrm{g}$, validating the UAE as an ideal extraction technique for obtaining the compounds of interest. The high coefficient $\mathrm{R}^{2}$ value for each extraction methodology, higher than 0.9 for most of the analysed responses, and the nosignificant difference between predicted and experimental values demonstrated the validity of the proposed optimization model.

Finally, we can highlight that this study reports the use of G. globosa as a source of betacyanin compounds in an optimized UAE system that would assist in the production of extracts with important colourant properties, thus with high potential to be used as natural colorant additives.

\section{Acknowledgements}

The authors thank the Foundation for Science and Technology (FCT, Portugal) and FEDER under Programme PT2020 for financial support to CIMO (UID/AGR/00690/2013) and L. Barros (SFRH/BPD/107855/ 2015) and C.L. Roriz (SFRH/BD/117995/2016) grants. This work was also financially supported by: Project POCI-01-0145-FEDER-006984 Associate Laboratory LSRE-LCM funded by FEDER through COMPETE2020 - Programa Operacional Competitividade e Internacionalização (POCI) and by national funds through FCT Fundação para a Ciência e a Tecnologia. To Xunta de Galicia for financial support for the post-doctoral researcher of M.A. Prieto. The authors also thank Ana Maria Carvalho for the plant donation. 


\section{Appendix A. Supplementary data}

Supplementary data associated with this article can be found, in the online version, at http://dx.doi.org/10.1016/j.indcrop.2017.05.008.

\section{References}

Albuquerque, B.R., Prieto, M.A., Barreiro, M.F., Rodrigues, A., Curran, T.P., Barros, L., Ferreira, I.C.F.R., 2016. Catechin-based extract optimization obtained from Arbutus unedo L. fruits using maceration/microwave/ultrasound extraction techniques. Ind. Crops Prod. 95, 404-415.

Arnao, M.B., Cano, A., Acosta, M., 2001. The hydrophilic and lipophilic contribution to total antioxidant activity. Food Chem. 73, 239-244.

Bezerra, M.A., Santelli, R.E., Oliveira, E.P., Villar, L.S., Escaleira, E.A., Escaleira, L.A., 2008. Response surface methodology (RSM) as a tool for optimization in analytical chemistry. Talanta 76, 965-977.

Bhuyan, D.J., Van Vuong, Q., Chalmers, A.C., Van Altena, I.A., Bowyer, M.C., Scarlett, C.J., 2015. Microwave-assisted extraction of Eucalyptus robusta leaf for the optimal yield of total phenolic compounds. Ind. Crops Prod. 69, 290-299.

Box, G., Hunter, J., 1957. Multi-factor experimental designs for exploring response surfaces. Ann. Math. Stat. 28, 195-241.

Box, G.E.P., Hunter, J.S., Hunter, W.G., 2005. Statistics for Experimenters: Design, Innovation, and Discovery. John Wiley Sons Inc.

Cardoso-Ugarte, G.A., Sosa-Morales, M.E., Ballard, T., Liceaga, A., Martín-González, M.F.S., 2014. Microwave-assisted extraction of betalains from red beet (Beta vulgaris). LWT-Food Sci. Technol. 59, 276-282.

Chavan, Y., Singhal, R.S., 2013. Ultrasound-assisted extraction (UAE) of bioactives from arecanut (Areca catechu L.) and optimization study using response surface methodology. Innov. Food Sci. Emerg. Technol. 17, 106-113.

Comuzzi, C., Polese, P., Melchior, A., Portanova, R., Tolazzi, M., 2003. SOLVERSTAT: a new utility for multipurpose analysis: an application to the investigation of dioxygenated Co (II) complex formation in dimethylsulfoxide solution. Talanta 59, 67-80.

Dahmoune, F., Nayak, B., Moussi, K., Remini, H., Madani, K., 2015. Optimization of microwave-assisted extraction of polyphenols from Myrtus communis L. leaves. Food Chem. 166, 585-595.

Dai, J., Mumper, R.J., 2010. Plant phenolics: extraction, analysis and their antioxidant and anticancer properties. Molecules 15, 7313-7352.

Delgado-Vargas, F., Jiménez, A.R., Paredes-López, O., 2000. Natural pigments: carotenoids, anthocyanins, and betalains-characteristics, biosynthesis, processing, and stability. Crit. Rev. Food Sci. Nutr. 40, 173-289.

Gengatharan, A., Dykes, G.A., Choo, W.S., 2015. Betalains: natural plant pigments with potential application in functional foods. LWT Food Sci. Technol. 64, 645-649.

Heleno, S.A., Diz, P., Prieto, M.A., Barros, L., Rodrigues, A., Barreiro, M.F., Ferreira, I.C.F.R., 2016. Optimization of ultrasound-assisted extraction to obtain mycosterols from Agaricus bisporus L. by response surface methodology and comparison with conventional Soxhlet extraction. Food Chem. 197, 1054-1063.

Hossain, M.B., Tiwari, B.K., Gangopadhyay, N., O’Donnell, C.P., Brunton, N.P., Rai, D.K., 2014. Ultrasonic extraction of steroidal alkaloids from potato peel waste. Ultrason. Sonochem. 21, 1470-1476.

Huffman, B.A., Poltash, M.L., Hughey, C.A., 2012. Effect of polar protic and polar aprotic solvents on negative-ion electrospray ionization and chromatographic separation of small acidic molecules. Anal. Chem. 84, 9942-9950.

Junqueira-Goncalves, M.P., Cardoso, L.P., Pinto, M.S., Pereira, R.M., Soares, N.F., Miltz, J., 2011. Irradiated beetroot extract as a colorant for cream cheese. Radiat. Phys. Chem. 80, 114-118.
Kala, H., Mehta, R., Sen, K., Tandey, R., Mandal, V., 2016. Trends in Analytical Chemistry Critical analysis of research trends and issues in microwave assisted extraction of phenolics: have we really done enough. Trends Anal. Chem. 85, 140-152.

Kalil, S., Maugeri, F., 2000. Response surface analysis and simulation as a tool for bioprocess design and optimization. Process Biochem. 35, 539-550.

Kemmer, G., Keller, S., 2010. Nonlinear least-squares data fitting in Excel spreadsheets. Nat.Protocols 5, 267-281.

Kislik, V.S., 2012. Solvent extraction. Solvent Extraction. pp. 185-314.

Klein-júnior, L.C., Vander, Y., Teresinha, A., 2016. Trends in Analytical Chemistry Enlarging the bottleneck in the analysis of alkaloids: a review on sample preparation in herbal matrices. Trends Anal. Chem. 80, 66-82.

Li, H., Deng, Z., Liu, R., Zhu, H., Draves, J., Tsao, R., 2015. Characterization of phenolics, betacyanins and antioxidant activities of the seed, leaf, sprout, flower and stalk extracts of three Amaranthus species. J. Food Compos. Anal. 37, 75-81.

Maran, J.P., Priya, B., Nivetha, C.V., 2015. Optimization of ultrasound-assisted extraction of natural pigments from Bougainvillea glabra flowers. Ind. Crops Prod. 63, 182-189.

Martins, N., Roriz, C.L., Morales, P., Barros, L., Ferreira, I.C.F.R., 2016. Food colorants: challenges, opportunities and current desires of agro-industries to ensure consumer expectations and regulatory practices. Trends Food Sci. Technol. 52, 1-15.

Pavlov, A., Bley, T., 2006. Betalains biosynthesis by Beta vulgaris L. hairy root culture in a temporary immersion cultivation system. Process Biochem. 41, 848-852.

Pinela, J., Prieto, M.A., Barreiro, M.F., Carvalho, A.M., Oliveira, M.B.P.P., Vázquez, J.A., Ferreira, I.C.F.R., 2016a. Optimization of microwave-assisted extraction of hydrophilic and lipophilic antioxidants from a surplus tomato crop by response surface methodology. Food Bioprod. Process. 98, 283-298.

Pinela, J., Prieto, M.A., Carvalho, A.M., Barros, L., Maria, A., Filomena, M., Ferreira, I.C.F.R., 2016b. Microwave-assisted extraction of phenolic acids and flavonoids and production of antioxidant ingredients from tomato: a nutraceutical-oriented optimization study. Sep. Purif. Technol. 164, 114-124.

Prieto, M.A., Vázquez, J.A., 2014. In vitro determination of the lipophilic and hydrophilic antioxidant capacity of unroasted coffee bean extracts and their synergistic and antagonistic effects. Food Res. Int. 64, 1183-1196.

Prikler, S., 2009. 2nd ed. Robert de Levie: Advanced Excel for Scientific Data Analysis, vol. 395. pp. 1945 Anal. Bioanal. Chem.

Roriz, C.L., Barros, L., Carvalho, A.M., Santos-Buelga, C., Ferreira, I.C.F.R., 2014. Pterospartum tridentatum, Gomphrena globosa and Cymbopogon citratus: a phytochemical study focused on antioxidant compounds. Food Res. Int. 62, 684-693.

Roriz, C.L., Barros, L., Prieto, M.A., Morales, P., Ferreira, I.C.F.R., 2017. Floral parts of Gomphrena globosa L. as a novel alternative source of betacyanins: optimization of the extraction using response surface methodology. Food Chem. 229, 223-234.

Routray, W., Orsat, V., 2012. Microwave-assisted extraction of flavonoids: a review. Food Bioprocess Technol. 409-424.

Silva, L.R., Valentão, P., Faria, J., Ferreres, F., Sousa, C., Andrade, P.B., 2012 Phytochemical investigations and biological potential screening with cellular and non-cellular models of globe amaranth (Gomphrena globosa L.) inflorescences. Food Chem. 135, 756-763.

Stagnari, F., Galieni, A., Speca, S., Pisante, M., 2014. Water stress effects on growth, yield and quality traits of red beet. Sci. Hortic. (Amst.) 165, 13-22.

Sultana, B., Anwar, F., Ashraf, M., 2009. Effect of extraction solvent/technique on the antioxidant activity of selected medicinal plant extracts. Molecules 14, 2167-2180.

Thirugnanasambandham, K., Sivakumar, V., 2015. Microwave assisted extraction process of betalain from dragon fruit and its antioxidant activities. J. Saudi Soc. Agric. Sci 1-8.

Tiwari, B.K., 2015. Ultrasound: a clean, green extraction technology. TrAC Trends Anal. Chem. 71, 100-109.

Vulić, J., Čanadanović-Brunet, J., Ćetković, G., Tumbas, V., Djilas, S., Četojević-Simin, D., Čanadanović, V., 2012. Antioxidant and cell growth activities of beet root pomace extracts. J. Funct. Foods 4, 670-678. 